\title{
Self Medication Practices: Insights from Caregivers to Their Under Five Children in Southwestern Nigeria
}

Oluseye Okunola ( $\square$ oaokunola@oauife.edu.ng )

Obafemi Awolowo University

Mabayoje Anthony Aluko

Obafemi Awolowo University

Abdulrahman Aroke

Obafemi Awolowo University

\section{Research Article}

Keywords: caregivers, self-medication, Thematic analysis, ATLAs Ti package

Posted Date: December 3rd, 2021

DOI: https://doi.org/10.21203/rs.3.rs-1062158/v1

License: (c) (i) This work is licensed under a Creative Commons Attribution 4.0 International License.

Read Full License 


\section{Abstract}

The act of childcare by caregivers requires meticulous attention especially to under-five children in any clime. This paper aggregates the understanding of caregivers on the practice of self-medication to their

under-five children. A qualitative approach using Focus group discussions among selected caregivers to under-five children in Osun and Lagos states of southwestern states of Nigeria was used for data collection. Thematic analysis was done with the assistance of the ATLAs Ti package. The caregivers' understanding of the practice included; re-use of medications based on previous illnesses, use of familiar drugs, and use of medications without conducting any laboratory investigations. Also they ascribed the practice to the use of medication for minor ailments only and largely on their individual perception of their under-five children. Most caregivers were knowledgeable of the practice though in diverse contexts, thereby provided different social milieu for the practice. In the overall, the study revealed the caregivers' different understanding of what self-medication practice to their under-five children are.

\section{Introduction}

The perception of self-medication practice by caregivers to their under-five children needs to be assessed. Nworie, Aluh,Eze, Opurum, Ndubuisi, Unuavworhuo, Ozoh and Ezeh (2018), reported different ways in which mothers understand what self-medication meant to them. These include, consulting a doctor if symptoms of an illness are not relieved, using left over drugs for future illness, and also perceived it that only doctors should give the right to use drugs. These showed that the mothers were knowledgeable of the practice but in different contexts. However, in a descriptive cross sectional study performed to understand the perceptions and practices about self-medication among college medical students in Pakistan located in Multan, by (Noor, Sahu, Abdullah, and Yousaf, 2017) various perceptions were noted. About $24.2 \%$ of them acknowledged it as a good practice, $42.1 \%$ of them identified with it as an acceptable practice and $33.7 \%$ of the students reported it to be unacceptable practice.

Suja, Dutta, and Swaroop, (2019) highlighted that most (73.3\%) residents in an urban slum in India were highly knowledgeable that self-medication means the use of medication without doctor's consent. This was a cross-sectional observational study with the aim to assess the knowledge and attitude of selfmedication practices among the residents of an urban community. Though the participants were not specifically the caregivers of under-five children but constituted individuals engaged with the practice. Hence, they demonstrated considerable understanding of what self-medication practice could be.

Among pregnant women in Northern Nigeria by (Attahiru, Awosan, Hassan, and Arisegi, 2018), it was reported that almost all of them (98.4\%) were aware of self-medication to be use of drug without prescription from a qualified doctor and less than half perceived it as a serious threat to their health and the health of their unborn baby. This signified that most pregnant women had a moderate understanding of what the practice is and its attendance complication. 
Muoneke et al., (2018) in his assessment of caregivers' perception of self-medication practice to their under-five children during febrile illness revealed divergent views on the practice. It was reported that as much as $92.0 \%$ of the parental figures attested that self-medication for febrile conditions in kids who were underneath 5 years was vital. Thirty-two percent additionally said that administration of fever drugs never recommended by a specialist was inescapable and vital. While, $71.0 \%$ guardians announced that they don't typically counsel specialists for solution of medication for the feverish condition of kids beneath 5 years old consistently, as much as (85.5\%) parental referenced that they utilized medications recently endorsed for fever in dealing with the kids. Medicines and herbs utilization were simply the commonest prescription practices among the caregivers as $91.0 \%$, enjoy such separately. One hundred and eight (48.9\%) parental figures avowed that self-prescription for fever kept going as long as the patent medication/customary healer suggested. Evidently, the study pointed out that the majority of the caregivers vividly understand what the practice is, though in different dimensions.

\section{Objective}

To assess caregivers' knowledge of self-medication practices to under-five children in Southwestern Nigeria.

\section{Research Design}

\section{Study Design and Locations}

Qualitative exploratory design was used to explore the self-medication practices by the caregivers to their under-five children in the study area.

Considering the nature of this research study design and the research questions, for the study to have a general representation of the states in south-western Nigeria, two states were selected for the study based on the cosmopolitanism and non-cosmopolitanism nature of the states. The south-western (SW) Nigeria comprises of six states which are predominantly of the Yoruba tribe (Ajala, 2009). The language generally speaking in this region is major, Yoruba language. Culturally these states are homogenous. However, there are some features which differentiate the states such as level of commercialization, population density, religion, land mass, and different cultural practices (Ajala, 2009). The six states in this region are Lagos, Ogun, Oyo, Osun, Ekiti, and Ondo states. Among them, Lagos and Osun states were selected for the study.

\section{Study Population}

This study engaged the caregivers to under-five children within the household. The caregivers in this study refer to any individual that is directly involved in the treatment of the under-five children during illness or diseased period in the house. This may be mothers, fathers, siblings, housemaid, grandparents, neighbors, foster parents, relatives or as it exists during the study.

\section{Sampling Technique}


For the qualitative design, a purposively snowballing technique was used to select the respondents in the study area with the aid of people of influence in the community for the FGDs. The 12 FGDs were stratified into younger caregivers and older caregivers. Each FGD consisted of 6-8 caregivers, and the sessions were conducted until the level of saturation was attained.

\section{Data Collection}

In the study of this nature, the qualitative data were collected using the FGD with the aid of FGD guide for the caregivers of U- 5 children and with the assistance of audio-tape receiver to obtain relevant information from those involved in the practice of self-medicating to the caregivers of the U-5 children.

\section{Data Analysis}

The data was analyzed based using a thematic analysis. This was developed by the use of codes based on the identified variables from the fieldwork. FGD and the interview were transcribed verbatim and classified into different themes. The data or information from the qualitative design was analyzed with the aid of Nvivo 11.0, a software designed for the analysis of qualitative data.

\section{Result}

Table 1: Distribution of Discussants by Socio-Demographic Characteristics 


\begin{tabular}{|c|c|c|c|c|c|c|}
\hline $\begin{array}{l}\text { Socio- } \\
\text { demographic } \\
\text { characteristics }\end{array}$ & Freq. (\%) & & \multicolumn{3}{|l|}{ Freq.(\%) } & \multirow[t]{2}{*}{ Freq.(\%) } \\
\hline Age (years) & & \multicolumn{2}{|l|}{ Gender } & \multicolumn{2}{|c|}{ Marital Status } & \\
\hline $19-29$ & $22(25.6)$ & Male & $26(30.2)$ & \multicolumn{2}{|l|}{ Married } & $86(100.0)$ \\
\hline $30-39$ & $44(51.2)$ & Female & $60(69.8)$ & \multicolumn{2}{|c|}{ Ages of Children } & \\
\hline $40-49$ & 14(16.3) & \multicolumn{2}{|c|}{ Number of Children } & Age(years) & Freq.(\%) & $\begin{array}{l}\% \text { of } \\
\text { Cases }\end{array}$ \\
\hline $50-59$ & $6(7.0)$ & $<2$ & $10(11.6)$ & $<1$ years & $30(16.3)$ & $34.9 \%$ \\
\hline Total & $86(100.0)$ & $2-4$ & $64(74.4)$ & 1-2years & $42(22.8)$ & $48.8 \%$ \\
\hline Family Size & & 5 and above & $12(14.0)$ & 3-4years & $58(31.5)$ & $67.4 \%$ \\
\hline 3 & 10(11.6) & Total & $86(100.0)$ & $>$ 5years & $54(29.3)$ & $62.8 \%$ \\
\hline $4-6$ & $66(76.7)$ & \multicolumn{2}{|c|}{ Educational Level } & Total & $184(100.0)$ & $214.0 \%$ \\
\hline 7 and above & 10(11.6) & $\begin{array}{l}\text { No formal } \\
\text { Education }\end{array}$ & $4(4.7)$ & Religion & & \\
\hline Total & $\begin{array}{l}86 \\
(100.0)\end{array}$ & $\begin{array}{l}\text { Primary } \\
\text { school }\end{array}$ & $12(14.0)$ & Christian & & $46(53.5)$ \\
\hline Occupation & & $\begin{array}{l}\text { Junior high } \\
\text { school }\end{array}$ & $6(7.0)$ & Islam & & $40(46.5)$ \\
\hline Official & 10(11.6) & $\begin{array}{l}\text { Senior high } \\
\text { school }\end{array}$ & $38(44.2)$ & Total & & $86(100.0)$ \\
\hline Self-employed & $60(69.8)$ & University & $26(30.2)$ & \multicolumn{2}{|c|}{ Place of Residence } & \\
\hline Housewife & $8(9.3)$ & Total & $86(100.0)$ & Urban & & $42(48.8)$ \\
\hline Unemployed & $8(9.3)$ & \multicolumn{2}{|c|}{ Family Monthly Income } & Rural & & $44(51.2)$ \\
\hline Total & $86(100.0)$ & $<\# 10,000$ & $10(11.6)$ & Total & & $\begin{array}{l}86 \\
(100.0)\end{array}$ \\
\hline \multicolumn{2}{|c|}{ Distance to Clinic (minutes) } & $\begin{array}{l}\# 10,000- \\
\# 30,999\end{array}$ & $28(32.6)$ & \multicolumn{2}{|c|}{ Medical Insurance } & \\
\hline$<10$ & $24(27.9)$ & $\begin{array}{l}\# 31,000- \\
\# 60,999\end{array}$ & $28(32.6)$ & Yes & & $6(7.0)$ \\
\hline 10 & $30(34.9)$ & $\begin{array}{l}\# 61,000- \\
\# 90,999\end{array}$ & $10(11.6)$ & No & & $80(93.0)$ \\
\hline 20 & 16(18.6) & $\begin{array}{l}\# 91,000- \\
\# 120,999\end{array}$ & $4(4.7)$ & Total & & $86(100.0)$ \\
\hline 30 & $12(14.0)$ & $\# 121,000$ & $6(7.0)$ & Existence o & Chronic Dis & es \\
\hline
\end{tabular}


and above

\begin{tabular}{|c|c|c|c|c|c|}
\hline $40-1 \mathrm{hr}$ & $2(2.3)$ & Total & $86(100.0)$ & Yes & $2(2.3)$ \\
\hline $\begin{array}{l}\text { Do not go to the } \\
\text { hospital }\end{array}$ & $2(2.3)$ & & & No & $84(97.7)$ \\
\hline Total & $86(100.0)$ & & & Total & $86(100.0)$ \\
\hline
\end{tabular}

The socio-demographic features of the respondents indicated that the mean age of the 86 respondents was $35.63 \pm 7.55$ years (range of 19-52 years). The respondents between ages $19-29$ were $25.6 \%, 51.2 \%$ were between ages 30-39, 16.3\% were between ages $40-49$ and $7.0 \%$ were between ages $50-59$ years of age. There were more female $(69.8 \%)$ than male (30.2\%) and all the respondents were married. The majority of the respondents (74.4\%) had two to four children. More so, $11.6 \%$ and $14.0 \%$ had less than two and above five children respectively. Regarding ages of children, forty-three of the respondents identified that they had at least one child that was less than one, aged one-two, aged three-four and aged five and above years. Also, the highest ages of children (67.4\%) were between the ages of three-four years. Besides, majority of the respondents $(74.4 \%)$ had a family size of four-six.

Furthermore, $53.5 \%$ were Christians, and $46.5 \%$ were Islam. About their educational qualification obtained and occupation, the majority of the respondents $(44.2 \%)$ had a senior high school qualification, and $69.8 \%$ were self-employed. About $48.8 \%$ of the respondents lived in the urban center, and $51.2 \%$ of the respondents lived in the rural center. Regarding family monthly income, $32.6 \%$ and $32.6 \%$ had an income of $\# 10,000$ - \#30,999 and $\# 31,000$ - \#60,999 monthly respectively. Majority of the respondents (93.0\%) had no medical insurance. As regard to distance from residence to clinic and existence of the chronic disease, $34.9 \%$ noted that the distance from house to clinic was 10 minutes and $97.7 \%$ stated that there was no existence of chronic diseases in the family.

This objective assessed the knowledge of self- medication practice to under-five children among the caregivers by asking questions based on their understanding of the phenomenon, and their perception of under-five children. These questions are needed to really make a good assessment of their knowledge of self-medication practices.

\section{Understanding of Self-Medication}

\section{Re-use of medicines based on someone else previous illness}

The study explored the respondents understanding of self-medication. From the literature, self-medication is when patient did not go to the hospital to find out the cause or getting a doctor's prescriptions before using any drug. Some respondents described self-medication as the re-use of medicines based on someone else previous illness, (they also subscribed to have different medicines at home in case the child falls in) as revealed in these excerpts: 
"If for example, someone has an issue, he can say her aunty too used the same drug and she decided to use the drugs as well". (Rural Female, Lagos 2)

"With the way I looked at self-medication at times, too-know can make someone to do self-medication may be we have known about one leaf or drug that we have use or someone use it and talked about it and we also know how the drug was effective so we too will copy the same". (Urban male, Osun State, Ref Civil Servant).

\section{The use of familiar drugs}

Some argued self-medication to be the use of familiar drugs_whenever their children took ill, as seen in these excerpts:

"It means using drugs we are familiar with from the beginning, like paracetamol and other drugs. Most times we buy them and keep them at home in case any sickness or body pain arises, we will just pick it up to use it. Even for the children, we use them." (Rural Female, Lagos 2.

"My view is if the drug has been giving in the hospital before one can go for it". (Rural Female, Osun 2).

\section{Use of medication without laboratory test}

It was meant to be using medication without laboratory test to ascertain the cause of illness, as affirmed by some caregivers. The respondents attached the use of medication to sequel to a confirmatory test for a definitive ailment. These can be deduced from these excerpts:

"But some people if anything happens to them now, they will take paracetamol, another small thing, they will take paracetamol. So, those ones are self-medication. When the headache is becoming common, the person should go and see the doctors and undergo a test to really know the cause of the headache especially if it is occurring like three times. It could be due to malaria or typhoid or anything else, this will determine the prescription of the doctors". (Rural Female, Lagos 1).

"Self-medication is not good they might need to run the test in the laboratory to confirm the illness before giving anything" (Rural Female, Osun 2).

\section{Taking drugs without doctor's consent}

Also, other participants were of the opinion or understanding that self-medication equals to taking drugs without doctor's consent. This statement signifies the WHO definition or meaning of self-medication. The real meaning was however indicated in their excerpts:

" ..... if anything happens to a child one needs to see the doctor for instant now if you want to sow a cloth you will take it to the tailor or if it is to build house you will call building so thing like that leads to life we should take it there". (Rural Male, Osun). 
"My understanding is that self-medication is the drug that we do not get the prescription from the doctors and it do affect the children. It is better we take the case to the hospital and whatever drug given is what we should use and we must follow the description". (Urban Female, Lagos State 1).

"My first born, maybe he is having high temperature or something, I will go and buy malaria drug for him not just from anyhow chemist but in a good pharmacy." (Urban Female, Lagos 3).

\section{Use of Medicine for Minor Ailment}

Among other respondents, their understanding of the phenomenon includes the use of_Medicine for Minor Ailment:

"......if it is a minor thing, not the kind of sickness that grips the child seriously, if it is something that you don't have an understanding of, you may not want to use self-medication but if it is a minor thing that you can handle or you have been handling such before and the drug you have been using is working, then you use self-medication". (Rural Female, Lagos 1).

In general, from the respondents, they have good understanding of what self-medication means, however it was expressed in different contexts but still attributing it to the concept of self-medication. It could be seen that this practice is very rampant among the participants as it conveyed different categories of practicability in the community. This will contribute immensely to the caregivers' body of knowledge of self-medication practice, because the meaning attributed to a practice will determine to a great extent how it will be practiced whether good or bad.

\section{Perception of under-five children by caregiver}

In assessing caregiver's knowledge of self-medication practice to the under-five children, a little digression was done to examine how the caregivers perceived the under-five children. Respondents were asked how they perceived under-five. Perception in the sense the way they self-medicate to these category of children. In other to determine the form of healthcare practice to these children, the perception of the under-fives by the caregivers most likely will inform the management of the children during illness. The participants in their own view perceived the children to be fragile as they were likened to a mirror or glass, or egg which needs to be handled with extra care or caution.

"I think we should look at them like an egg. Egg in the sense that you cannot drop an egg on a harsh place will break. You cannot drop the off in a shaking place it will break. It will fall down and break. You should actually watch what they take, wash them properly and make sure they are well clean; make sure they don't put dirt in their mouth..." (Rural Female, Lagos 2)

"I see these children we are talking of as fragile children they are like Yoruba will call "dingi". Something that is fragile that we need to take care of it very well, example like some one that is feeling hungry and this person cannot talk, all what they know how to do is to cry". (Urban, Male, Civil Servant, Osun 1) 
".... that they are like fragile things if we take care of them very well they are our tomorrow because we too we have pass through that stage before and our parents too take good care of us". (Urban male, Osun 1).

"I know that they are fragile children that we should not jeopardise their future I you see a new born baby of today, it is not possible for him to call the mother and say I have headache..." (Urban male, Osun State 1).

“.... under-five children are fragile, they cannot express themselves that this is what they are passing through. That is the reason why we usually take care of them very well." (Urban Female, Osun 1).

The participants in the FGD narrated that, the under-five children most times cannot express themselves as they are helpless and need to be support. The following narratives reveal:

"... the children are very small and they cannot express themselves and even if they will explain, they may not be able to say it deeply the way it affects them." (Rural Female, Lagos 1)

"....all know that children normally play so we know that there is no other sickness they will have except to have temperature and they cannot explain if they are having headache or stomach ache, so as at any time they can have temperature it might be in the morning or afternoon."(Urban Female, Osun 2).

Children generally under the parental or caregivers control, need to be guided and monitored adequately. Even as this applies to the older children, nothing sorts of or less than this must be meted to the vulnerable under-five groups. This is evident in the discussion of the participants while explaining their own view of perception of under-five children. This position was articulated in different ways among the FGD participants:

"My view is they are still small and anything they do we need to be monitoring them" (Rural Male, Osun)

"...they may not be able to say it deeply the way it affects them. That is why we as a parent must be very observant.... "(Rural Female, Lagos).

As caregivers, their ultimate responsibility is to care for the under-five children within their household.

This was also the perception of their under-five as enunciated in these excerpts:

"Whenever I discover that my child is not feeling well, I always want to act fast to make sure the child returns to the normal state of health" (Urban Female, Lagos 2).

"We need to take care of them. They cannot use the drug meant for the elderly because their system cannot absorb it. Medicine good for the adult can harm their own system. We should take good care of them and they should not play with a sharp object". (Rural Female, Lagos 2).

\section{Discussion}


Knowledge, attitude and practice of health behaviours mostly dictate the success or failure of such practices among its practitioners. This assessment of the practice was based on their own intuition and may perhaps determine the efficacy and the outcome of the practice. Various ideations and concepts were posited by the caregivers that culminated to their knowledge of the practice. Though, their understanding of the practice was saddled with different contextual reasons, nevertheless it still connotes a very good knowledge of self-medication practice. Some participants elicited that the practice of selfmedication essentially means the re-use of medicines based on the experience from past illnesses in the children. They expressed this view by attributing the practice to the experiences they garnered while managing or treating their wards during sickness episodes. Subsequent ailment among the children attracted the same pattern of treatment by their caregivers based on the management from the previous illnesses. This was corroborated by Nworie et al., (2018) where caregivers of under-five children interpreted self-care practice to imply the use of some left over medications from past illnesses. The significance of this idea most likely depends on the individual recall ability to vividly capture what was done when a child of theirs or someone close during a similar sickness episode. The recognition of the disease state in the children were assessed subjectively by the caregivers and treatment were based on the individual translation of the symptoms exhibited by the children. However, using the same line of treatment for the children during illness episode does not guarantee a successful outcome.

Self-medication practice was expressed by some of these participants to be the re-use of medicines based on their past encounter from previous illnesses. This means the use of any medicaments or let overs in the household arising from the past illnesses encountered by the children. The use of such products were based on the premise that the treatment outcome was good considering the use of the medicaments. Hence, most caregivers employed the same mechanisms to treat future illnesses in the children. This interpretation was confirmed by (Cruz M, Dourado L, Bodevan E, Andrade R, and Santos D, 2014; K. A. Oshikoya, Senbanjo, and Njokanma, 2009) from studies that identified the use of home management in treating child with colic and use of over-the -counter drugs. Also, (Allotey, Reidpath, and Elisha, 2004) corroborated the re-use of medicine as a form of social medication for control and maintenance of good health of their children. Reason adduced to the re-use of medicine is probably as a result of the individual remembrance of those medicines and the process of treating the children which could be likened to an individual factor.

Additional findings from the qualitative component revealed that the practice of self-medication symbolises the use of familiar drugs or medications to their under-five children whenever they are sick. Familiarity with the medications implies recurrent usage and availability of such products either in the household or neighbourhood whenever their children took ill. This school of thought by the caregivers was mainly because of the consistent usage of such medicines for treating various ailments among their children. This result confirmed the submission of Sasaki and Kamiya, (2015) which reported that the caregivers 'understanding of paediatric medication was based on their familiarity with such medications. Most female participants vividly concur with this conception of self-medication practice. As these drugs are in use due to their familiarity and non-prescription by a qualified physician, hence these duos constitute self-medication practice but in different context. This could be attributed to perceived efficacy, 
cheap cost, various advertisement of these medicaments in the media, and non-regulatory of such products by government institutions. The understanding of this practice from this finding depicts a considerable good knowledge of the practice as they used such medicines based on easy recognition aside getting a prescription from a physician.

In another parlance, findings from some participants interpreted the practice to the use of medication without laboratory tests. These group of participants fathomed self-medication to constitute not investigating the ailment through laboratory investigations. Therefore, to them using any medication without approaching the various diagnostic centres signifies self-medication. Laboratory investigation is part of the clinical procedures that are undertaken in the search for a probable cause of a disease condition and does not entail the medication to use and the procedures. However, lay people lack the technical knowledge that is required in interpreting laboratory evidence and diagnosis of a disease condition. Interpretation of such evidence depends on a professional physician who possess the knowledge and technical skills to read and the jargons of a laboratory scientist. This finding relates to the possible influence of biomedicine on health behaviour and the growing awareness around synthetic drugs. Respondents that are likely to have such understanding are slightly educated and familiar with modern or biomedicine. Such caregivers also appear inclined to have preference for evidence-based rationale before drug consumption or administration to their under-five children.

Furthermore, some discussants attributed their meaning of self-medication to taking drugs without doctor's consent. The act of using medications without the permission of a certified medical expert solely constitutes taking medicines without a prescription. Seeking the attention of a medical expert on illness condition of children could be met with bureaucracies at the health facilities or poor health system structures. This succinctly identifies with the WHO's definition of the self-medication practice. In as much as the caregivers revealed their comprehension of the practice to be this term, then it shows they are knowledgeable on the practice. According to Attahiru et al., (2018) and Suja et al., (2019) self-medication connotes usage of drugs without doctor's consent or doctor's prescription. But this does not imply the practice is done well or wrongly. This signifies probably the caregivers are aware of the pros and cons of engaging in self-medication practice without doctor's consent based on their experiences in childcare practice or increase in their level of education.

The level or degree of the disease condition in the under-five children was highlighted as part of the interpretation for the practice. Having cognizance of the extent of the severity of the disease is a dictum for self-medication in the event of a health challenge for an under-five child. Some participants attributed their understanding of self-medication practice to the degree of the children's disease state. They meant the practice to be the method of treatment only when there is a less severe illness in the children. Any other disease of higher severity was perceived to attract non self-medication practice. The use of medicine for perceived minor ailment by the caregivers was reflected as the picture for self-medication practice. This builds on the report by Nworie et al., (2018) that posited self-medication to be the practice done according to the degree of severity of the ailments in the under-five children. To this set of participants, illnesses of under-five children that are not severe were given non prescribed medications, 
hence conceiving the method of managing the extent of disease state in the children as self-medication practice.

In Overall, the finding generally depicted good conception of the knowledge of self-medication among the caregivers. This is in contrast to findings of Auta et al., (2012); Oshikoya et al., (2009) and Pavyde et al., (2015) who reported poor knowledge of self-medication practice among their respondents.

\section{Conclusion}

The act of childcare through self-medication is a well-established practice among caregivers in the study area. Most caregivers were knowledgeable of the practice though in diverse contexts, thereby provided different social milieu for the practice. In the overall, the study revealed the various sociological factors influencing the practice of self-medication to the under-five children. This practice was highly influenced by social, economic and individual factors.

\section{Policy Implication.}

This study recognises that the practice of self-medication to under-five children in the southwestern Nigeria has not been sufficiently studied to date. It further revealed how caregivers valued child care practice of their under-five children and various societal context that intervenes with the practice. Apart from the national policy that prevents the sales of some medicines over-the counter, though which is not very effective in Nigeria, there is need for household-based policy that specifically targets the caregivers to under-five children where they are enlightened on the use of drugs irrationally on their children. This idea was supported by caregivers' revelations rendered as part of the information gathering for this study. The goal is to a safe responsible self-medication practice in order to reduce the cost of care, reduce child mortality rate and improve on the quality of healthcare to the under-five children.

Caregivers are still dominated by social and traditional norms of child care practices as well as some unhealthy and unsafe methods of administering medicaments to their under-five children. This calls for public orientation and sensitization of caregivers on childcare health education. This could be done in form of public health awareness campaign by various stakeholders in the communities.

\section{Declarations}

\section{Ethical Permission}

Ethical clearance was gotten from the Health Research Ethics Committee Institute of Public Health, Obafemi Awolowo University, lle-Ife, Nigeria with the approval number HREC NO: IPHOAU/12/1194. The purpose of the study was explained to the participants prior to obtaining verbal and written consent. Their rights to withdrawal at any point was also emphasized. Throughout the study, confidentiality and privacy were maintained. Individual participant's responses were not also linked to ensure anonymity. 
All the procedure involving humans in this study was in accordance to guidelines of Declaration of Helsinki in the manuscript as approved by the Health Research Ethics Committee, Institute of Public Health, Obafemi Awolowo University, Ile-Ife, Nigeria.

\section{Consent for publication}

Not applicable

\section{Availability of data and materials}

The data are contained in the manuscript.

\section{Competing interests}

The author of this work hereby states that there are no competing interests whatsoever in any form as it regards this study.

\section{Authors' contributions}

OOA wrote the main manuscript while AMAO was my Supervisor and conceptualized the research topic and AAA collected the data and analyzed it.

\section{Acknowledgement and Funding}

This research was supported by the Consortium for Advanced Research Training in Africa (CARTA). CARTA is jointly led by the African Population and Health Research Center and the University of the Witwatersrand and funded by the Carnegie Corporation of New York (Grant No: B 8606.R02), Sida (Grant No: 54100113), the DELTAS Africa Initiative (Grant No: 107768/Z/15/Z) and Deutscher Akademischer Austauschdienst (DAAD). The DELTAS Africa Initiative is an independent funding scheme of the African Academy of Sciences (AAS)'s Alliance for Accelerating Excellence in Science in Africa (AESA) and supported by the New Partnership for Africa's Development Planning and Coordinating Agency (NEPAD Agency) with funding from the Wellcome Trust (UK) and the UK government.

\section{References}

1. Ajala, A. S. (2009). Yoruba Nationalist Movements, Ethnic Politics and Violence: A Creation from Historical Consciousness and Socio-political Space in South-western Nigeria (Issue 105).

2. Allotey, P., Reidpath, D. D., \& Elisha, D. (2004). "Social Medication" and the Control of Children: A Qualitative Study of Over-the-Counter Medication Among Australian Children. PEDIATRICS, 114(3). https://doi.org/10.1542/peds.2004-0759

3. Attahiru, A., Awosan, K. J., Hassan, M., \& Arisegi, S. A. (2018). Awareness, Risk Perception and Practice of Self-Medication Among Pregnant Women Attending Ante-Natal Clinics in Sokoto, Nigeria. Journal of Drug Delivery and Therapeutics, 8(4), 256-262. https://doi.org/10.22270/jddt.v8i4.1782 
4. Auta, A., Shalkur, D., Omale, S., \& Abiodun, A. (2012). Medicine Knowledge and Self-Medication Practice Among Students. African Journal of Pharmaceutical Research \& Development, 4(1), 6-11.

5. Cruz M, Dourado L, Bodevan E, Andrade R, \& Santos D. (2014). Medication use among children 0-14 years old: population baseline study $₫$. Jornal de Pediatria, 90(6), 608-615. https://doi.org/10.1016/j.jped.2014.03.004

6. Muoneke, V. U., Una, A. F., Mbachu, C., Eke, C. B., Ododo, C. I., Nkaleke, D. I., Anasi, V. C., \& Nwuzor, C. S. (2018). View of Caregivers' Perception and Practice of Self-medication for Fevers in Under-five Children_ A Cross-sectional Study in a Rural Community, South-East Nigeria.pdf. Journal of Advances in Medicine and Medical Research, 27(12), 1-12.

7. Noor, A., Sahu, E. H., Abdullah, M. U., \& Yousaf, A. (1970). Self-Medication Practices and Perceptions Among Undergraduate Medical Students of Multan Medical \& Dental College, Multan. Pakistan Journal of Public Health, 7(1), 58-61. https://doi.org/10.32413/pjph.v7i1.26

8. Nworie, K. M., Aluh, D. O., Ezeh, J., Ezeh, C. C., Opurum, C. A., Ndubuisi, L., Unuavworhuo, D., \& Ozoh, G. C. (2018). Assessment of Self-medication Practices for Treatment of Illnesses among Schoolchildren in Southeast, Nigeria. Matters of Behaviour, 3(4), 15-25.

9. Oshikoya, K. A., Senbanjo, I. O., \& Njokanma, O. F. (2009). Self-medication for infants with colic in Lagos, Nigeria. BMC Pediatrics, 9, 9. https://doi.org/10.1186/1471-2431-9-9

10. Pavyde, E., Veikutis, V., Maciuliene, A., Maciulis, V., Petrikonis, K., \& Stankevicius, E. (2015). Public Knowledge, Beliefs and Behavior on Antibiotic Use and Self-Medication in Lithuania. Int. J. Environ. Res. Public Health, 12, 7002-7016. https://doi.org/10.3390/ijerph120607002

11. Sasaki, E., \& Kamiya, Y. (2015). Caregivers' understanding of pediatric medication in central Malawi. Journal of Tropical Pediatrics, 61(1), 14-19. https://doi.org/10.1093/tropej/fmu057

12. SUJA, V. S., DUTTA, S., \& SWAROOP, A. M. (2019). Knowledge and Perceptions of Self-Medication Practices in an Urban Community. Asian Journal of Pharmaceutical and Clinical Research, 12(8), 42-45. https://doi.org/10.22159/ajpcr.2019.v12i18.33721 